\title{
Radio-echo probing of Black Rapids Glacier, Alaska, USA, during onset of melting and spring speed-up
}

\author{
Anthony M. GADES, ${ }^{*}$ Charles F. RAYMOND, Howard CONWAY \\ Department of Earth and Space Sciences, University of Washington, Seattle, WA, USA \\ E-mail: tony.gades@philips.com
}

\begin{abstract}
Radio-echo soundings were collected on Black Rapids Glacier, Alaska, USA, from mid-May to mid-July 1993 to investigate spring speed-up and summer slowdown including high-speed events associated with three lake drainages. Temporal changes in echo power from all depths were highly correlated, indicating a strong effect from varying amounts of near-surface water. Evaluation of bed reflectivity was corrected for this effect based on the time variation of spatially stable patterns of internal scattering identified using principal component analysis. Hourly time series collected at two fixed locations over the deepest part of two valley cross sections showed no detectable change in bed reflection power $(<5 \%)$ or phase $(<0.05 \mathrm{rad})$. Reoccupation of fixed locations toward the margins at several-day intervals revealed changes in bed power reflectivity up to $50 \%$, but with no definable relation to lake drainages. Theoretical analyses indicate that changes in reflectivity of $<5 \%$ from a rock bed constrain basal water thickness changes to centimeter scale or less. Conductive basal till degrades the constraint to decimeter scale or more. Changes in bed reflectivity of $50 \%$ indicate probable absence of thick conductive till at such locations, and that the changes were caused by centimeter to decimeter changes in equivalent water thickness.
\end{abstract}

\section{INTRODUCTION}

Hydraulic conditions in a glacier can exert strong control on its basal motion (Cuffey and Paterson, 2010). Long-known examples are the fast motion of some polar ice streams, the surging of glaciers and the seasonal variations in speed of temperate and polythermal glaciers. A diverse mix of observations provide a framework for understanding the breadth of these modes of velocity variation. These include direct sampling and instrumentation of the basal zone through boreholes or tunnels, remote sensing with seismic and radar methods, inference based on changes in surface motion including uplift, sampling of discharges in proglacial streams and investigation of deglaciated terrains. Fountain and Walder (1998) give a broad review; Mair and others (2003) and Bartholomaus and others (2008) provide a recent perspective on seasonal changes in speed. A central problem for advancing understanding is acquiring both spatial and temporal coverage of contemporaneous covariation of relevant variables describing the basal motion and hydraulic conditions. Radio-echo sounding (RES) is strongly motivated because of its capability for both high time resolution and rapid coverage of large spatial areas.

We performed a series of surface-based, low-frequency RES measurements in the upper ablation area of Black Rapids Glacier (BRG), Alaska, USA, (Fig. 1) to examine the changes in reflections from the interior and base of the ice on an hourly timescale associated with seasonal change in speed and shorter motion events. Measurements were carried out from mid-May to early July 1993 in conjunction with contemporaneous seismic reflection investigations by the University of Alaska Fairbanks (UAF; Nolan and Echelmeyer, 1999a).

Considerable success has been achieved on both polythermal and temperate glaciers of modest thickness with

*Present address: Philips Healthcare - Ultrasound, Bothell, WA, USA ground-penetrating radar (GPR) using frequencies of $25 \mathrm{MHz}$ and higher. GPR has been used to map water content in the ice (e.g. Murray and others, 2007; Bradford and others, 2009), which is relevant to transfer of water through the ice and its mechanical properties. GPR has also been used to detect changing intra- and basal-water conditions (e.g. Irvine-Fynn and others, 2006; Kulessa and others, 2008) relevant to our interest.

The $600 \mathrm{~m}$ thickness and temperate thermal regime of BRG motivated our use of low-frequency ( 2 and $5 \mathrm{MHz}$ ), short-pulse radar. At typical GPR frequencies, strong scattering from abundant meter-scale water bodies in temperate ice obstructs clear viewing through thick temperate ice to the bed. Low frequency reduces scattering from such water bodies, with their effect being smoothed into the bulk-ice water content. While thin water bodies and layers can be detected (e.g. Jacobel and Anderson, 1987; Walford and Kennett, 1989), sensitivity and resolution are less.

The primary challenges that emerge are shared generally by radar methods. Two such challenges are (1) strong nearsurface effects modifying the returns from all depths, which can give false indications of changes in the ice and at the bed, and (2) possible high background basal reflectivity from till, which can hide reflectivity changes from a drainage system between the till and ice base. Analysis of our data motivated a viable method for overcoming the first and provides perspective on the second.

\section{BLACK RAPIDS GLACIER}

BRG is $\sim 40 \mathrm{~km}$ long and $\sim 2.3 \mathrm{~km}$ wide (Fig. 1) with an average surface slope of $2.3^{\circ}$ (Heinrichs and others, 1996). It moves in a generally $U$-shaped valley with maximum ice depth of $\sim 700 \mathrm{~m}$ (Gades, 1998). The gently curving eastwest part of the valley $12-35 \mathrm{~km}$ from the head of the glacier follows the trace of the Denali Fault, separating distinct rock terranes to the north and south (Truffer and others, 1999). 


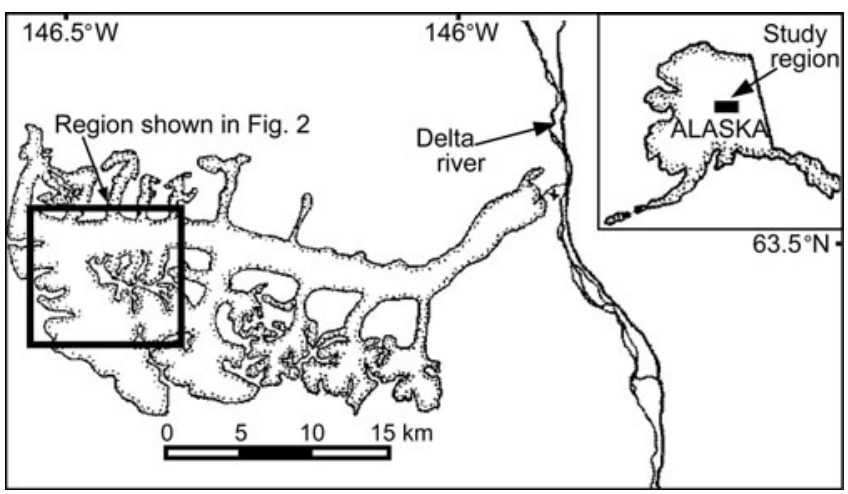

Fig. 1. Black Rapids Glacier and its location in Alaska (inset panel). The primary study region (heavy-lined box) is shown enlarged in Figure 2.

BRG is temperate (Harrison and others, 1973). It has surged in the past, most recently in 1936-37 (Post, 1960). During the past few decades there has not been a progressive evolution of geometry and speed that would indicate buildup to the next surge (Heinrichs and others, 1996; Truffer and others, 2005). The pattern of water and sediment discharge from the glacier does not show distinctive features related to the glacier's surge history (Raymond and others, 1995).

Much attention has focused on seasonal changes in speed in the upper part of the ablation area below the sharp bend in the main flow (Fig. 2). UAF photogrammetric velocity monitoring, started in 1982, identified an annually repeating pattern of spring speed-up and summer slowdown accompanied by motion events on shorter timescales (personal communication from W.D. Harrison, 1993). Approximately

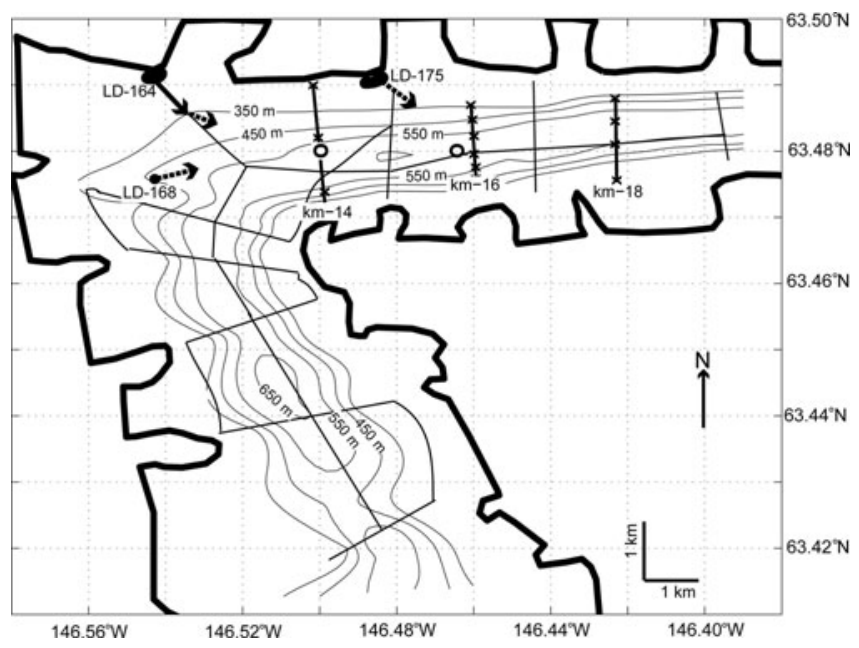

Fig. 2. BRG study region. Thick curve shows outline of the glacier. $\mathrm{km}-\mathrm{XX}$ indicates distance from the head of the glacier. Circles show locations of continuous RES monitoring of internal and bed reflections. Thicker straight lines show profiles, where repeated measurements were made. ' $x$ 's show locations on profiles of repeated stationary measurements. Light lines show paths of RES traverses to map surface elevation and ice thickness (Gades, 1998, ch. 4). Contours show unmigrated two-way travel time converted to distance based on an assumed speed of $168 \mathrm{~m} \mathrm{\mu s}^{-1}$ in pure, temperate ice not accounting for presence of water. Black patches show lake positions labeled with date of drainage initiation. Arrows show direction of over-surface drainage (solid) and assumed subsurface (dashed).

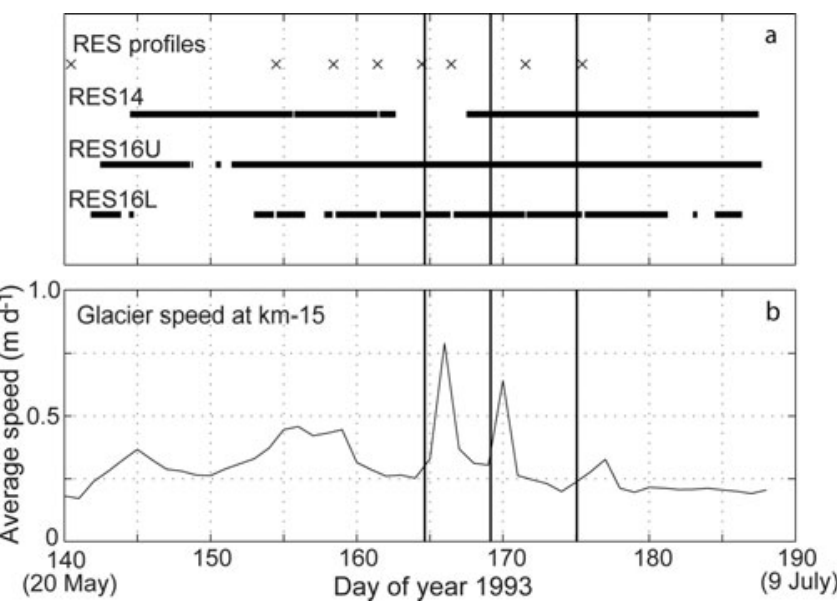

Fig. 3. (a) BRG measurement record and (b) daily average glacier speed at km-15. Vertical lines show the approximate onsets of marginal lake drainages. The speed measurements were gathered in collaboration with Nolan and Echelmeyer (1999a).

day-long, strongly peaked motion events are associated with rapid drainages of marginal or supraglacial lakes up-glacier from $\mathrm{km}-16$ that fill during the early melt season. Some less pronounced multi-day motion events are not so associated. Figure 3 shows the speed changes and the timing of lake drainages observed in our interval of observations during the early melt season of 1993 .

Seismic reflection experiments (Nolan and Echelmeyer, 1999a,b) and observations from boreholes drilled to the bed (Truffer and others, 1999) in a cross section $\sim 0.2 \mathrm{~km}$ downglacier from $\mathrm{km}-16$ have shown that the ice there is underlain by $4-7 \mathrm{~m}$ of till. Further, the experiments indicate that acoustic properties of the till can change rapidly in association with lake drainage events, and that deformation deep within the till, shearing concentrated in a thin layer just beneath the top of the till, and/or sliding over the top of the till all contribute in various combinations to the observed seasonal-scale variations in speed (Truffer and others, 2000; Truffer and Harrison, 2006).

Truffer and others (2001) analyzed some of these data and showed how high sensitivity of basal motion to small changes in basal water pressure and stress can explain the primary features of observed velocity change. Such sensitivity will arise from the presence of till close to or at failure under a large part of the glacier width, with stabilization provided by relatively small strong zones. More detailed analysis by Amundson and others (2006) has shown that increases in surface speed during spring and summer, and associated changes in the cross-glacier distribution of surface speed in comparison to winter, were related to redistribution of basal shear stress. Shear stress on the bed was reduced by $7 \%$ during spring and by $16 \%$ during summer in a zone $\sim 1 \mathrm{~km}$ wide centered $\sim 0.5 \mathrm{~km}$ left (north) of the deepest part of the cross section (Fig. 4).

\section{METHODS}

\subsection{RES system}

The RES systems consisted of a $\pm 1 \mathrm{kV}$ balanced impulse transmitter (Weertman, 1993) driving a resistively loaded, half-wavelength, center-feed dipole antenna and a receiver/ recorder sensing voltage on an identical antenna. Several 


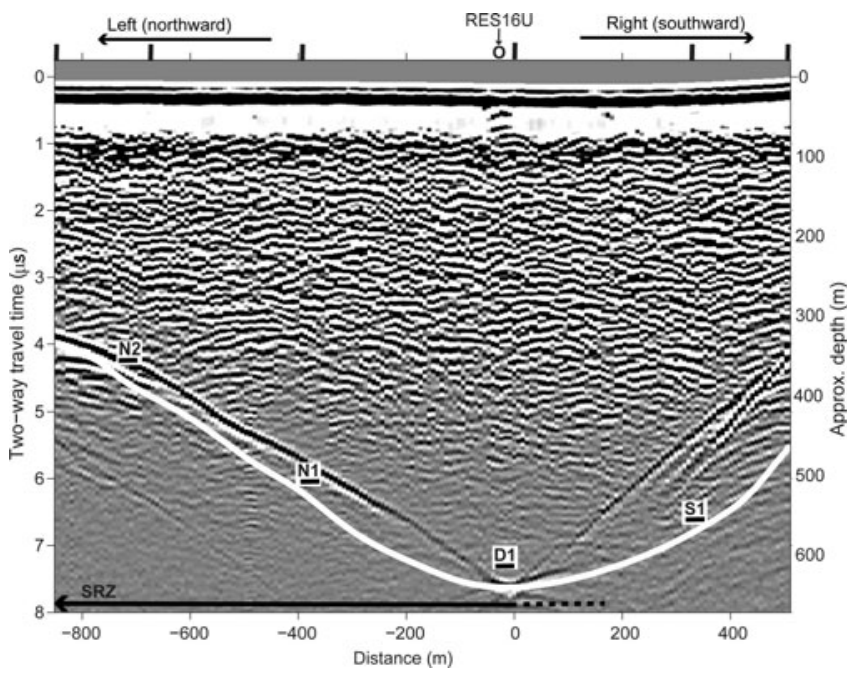

Fig. 4. Cross profile on 24 June 1993 looking down-glacier at km-16 displayed as a Z-scope image of received voltage. The horizontal axis is distance (northward to left, southward to right) for $\sim 86$ filtered records spaced $\sim 15.7 \mathrm{~m}$ across the $\sim 1354 \mathrm{~m}$ display width. Heavy ticks at top show transverse locations of measurement sites in the section named according to horizontal coordinate (Fig. 11). The circle indicates transverse location of RES16U $\sim 0.2 \mathrm{~km}$ upglacier from the section. The left axis is TWTT with zero adjusted accounting for surface elevation change determined with barometric leveling. Sampling interval is $10 \mathrm{~ns}$, giving a total of 740 samples in the TWTT in the $7.4 \mu$ s height between the upper surface and bed at the deepest location in the image. The white band near the surface is a consequence of near-field antenna interaction that is not completely removed by filtering and choice of grayscale mapping optimized to display later returns. The local signal emerging through this band beneath the location of RES16U is a consequence of interaction with antennas at RES16U and $16 \mathrm{~L}$ just up-glacier. The right axis is a distance corresponding to travel time calculated with assumption of uniform radar wave speed of $168 \mathrm{~m} \mathrm{ss}^{-1}$ in pure, temperate ice not accounting for presence of water. The thick white curve is a two-dimensional migration of the bed reflection based on that wave speed. The short horizontal bars represent the ice base in UAF boreholes (Truffer and others, 1999) $0.2 \mathrm{~km}$ down-glacier relative to the vertical distance axis on right shown as if they were in the section. Holes are named according to Nolan and Echelmeyer (1999a). N1 and D1 definitely reached the ice base and penetrated till. There are two hole locations beyond the south edge of the diagram at about +500 and $+600 \mathrm{~m}$. The long horizontal bar shows the transverse range of the basal stress reduction zone inferred by Amundson and others (2006) in summer (solid) and spring (solid + dashed). Vertical exaggeration 1.47:1.

commercial digital-oscilloscope-computer combinations were used for receiving and recording. The length of the antennas determined center frequency. (Each leg of the dipole was one-quarter wavelength, either $20 \mathrm{~m}$ for $\sim 2 \mathrm{MHz}$ or $10 \mathrm{~m}$ for $\sim 5 \mathrm{MHz}$.) Antennas lay directly on the glacier surface in a common line with centers offset depending on frequency (either 80 or $40 \mathrm{~m}$ ). With a smooth bed, reflection power from the $\sim 600 \mathrm{~m}$ depth of the bed will return from an area approximated by the diameter of the first Fresnel zone ( $300 \mathrm{~m}$ or $200 \mathrm{~m})$.

During measurement, the transmitter sent pulses with a repetition rate of $\sim 100 \mathrm{~Hz}$. The oscilloscope was triggered by arrival of an airwave, which initiates acquisition of a 'waveform' composed of a sequence of equally time-spaced voltage 'samples' (512 at $20 \mathrm{~ns}$ interval or 1024 at $10 \mathrm{~ns}$ interval). The waveform included pre-trigger for noise analyses (typically $\sim 0.5 \mu \mathrm{s}$ ) and post-trigger to capture bed and later returns (typically $\sim 10 \mu \mathrm{s}$ ). Each 'record' represents an average of order 100 waveforms from multiple transmissions stacked internally in the oscilloscope to reduce system and environmental noise.

Effects from low-frequency, near-field antenna interaction and residual high-frequency noise not removed by stacking were reduced in each record by post-processing digital filtering using a zero-phase, forward-reverse fourth-order Butterworth bandpass filter (chosen to minimize distortion of amplitude and phase shift for frequencies within the passband of $1: 10 \mathrm{MHz}$ ). 'Filtered' records are used for display and analysis.

Here our main focus is detection of changes in the timing and strength of reflections, and we use the recorded twoway travel time (TWTT) without interpretation into travel distance. Precise positioning of the reflectors is not central to our purpose, and is hampered by the complex distribution of water present in temperate glaciers (Bradford and others, 2009).

\subsection{Repeat profiles}

To provide spatial context and track seasonal change, RES profiles were repeated along marked paths at km-14, km-16 and km-18 (Fig. 2) every few days during the interval of lake drainages but less frequently before and after (Fig. 3). The receiver/recorder used a Tektronix 2432 oscilloscope sampling at $10 \mathrm{~ns}$ and a pre-amplifier. Power for the oscilloscope was supplied by a gasoline generator. The shorter $5 \mathrm{MHz}$ antennas were used to enable easier change of direction at ends of profiles and towing in rough terrain. The in-line transmitter and receiver/recorder were towed behind a snowmobile. Records were acquired at a spacing of $\sim 15.7 \mathrm{~m}$ determined by a calibrated wheel, with each record composed of a stack gathered over that distance. Records were filtered as above for display and analysis. Figure 4 shows an example of the profile measurements at $\mathrm{km}-16$. (Images of all three cross-section profiles can be found in Gades (1998, figs 4.2-4.4), but note incorrect orientation of fig. 4.3 in that source.)

Features common to profiles at different times present problems for direct temporal intercomparison of bed reflection amplitude either in profiles as a whole or in records selected from them. Foremost, variability of about $\pm 30 \%$ between adjacent, along-profile records indicates mixing of spatial with temporal changes associated with imprecisely reproduced antennas positions, recording locations and associated stacking intervals from one profile time to another. The more than order-of-magnitude bed reflection amplitude variation from the deepest to the shallowest bed reflections across a profile together with the limited dynamic range of the recording system (10 bits) lead to clipping of the highamplitude reflections in shallower locations. This problem occurred in the early profiles; it was later eliminated by adopting a strategy for gain management.

For these reasons, the profiling system was stopped and precisely positioned for stationary recording at 13 marked locations (Fig. 2). At these sites the number of successful records is six (at the three locations on $\mathrm{km}-14$ and at the six locations on $\mathrm{km}-16$ ) to four (at the four locations on $\mathrm{km}-18$ ).

\subsection{High-resolution time series}

Our main effort was directed toward identifying sub-daily changes in reflection characteristics with continuous high 


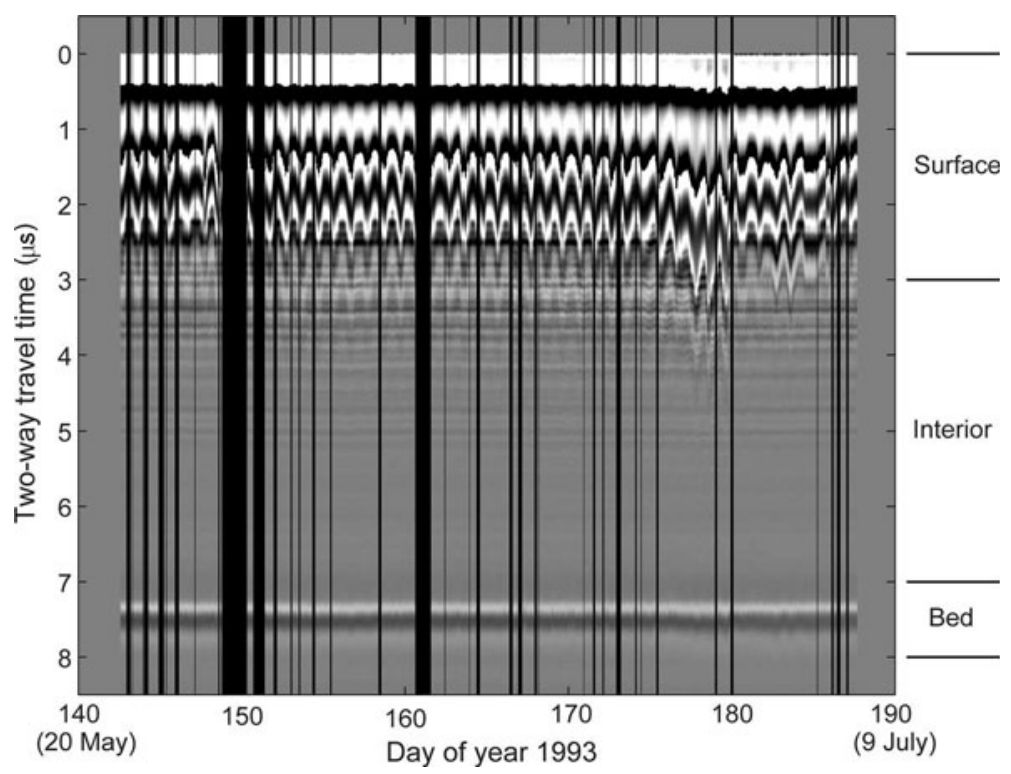

Fig. 5. Filtered data from RES16U displayed as a Z-scope image. The horizontal axis is the observation time (day of year) for $N=1747$ records. Vertical black bands are intervals when records were not acquired. The vertical axis is reflection TWTT for $m=512$ samples spaced 20 ns apart. Grayscale is related to the voltage amplitude of the reflection. The divisions into surface, interior and bed sample regions are labeled along the right vertical axis.

time resolution of $0.5-1$ hour time sampling. This was achieved with automated systems at fixed locations (Fig. 2) near the deepest part of the valley at km-14 (RES14) and $\sim 0.2 \mathrm{~km}$ up-glacier from km-16 (RES16) with intervals of recording shown in Figure 3. Battery banks charged with solar panels provided power for both transmitter and receiving/recording. At each location, $\sim 2 \mathrm{MHz}$ antennas were left in place on the glacier surface without disturbance other than from surface melting and gradual displacement by motion $<20$ m down-glacier over the measurement interval. Sites were visited once or twice daily to download data and to correct any problems with antennas or power supply.

The primary recording site near $63.48^{\circ} \mathrm{N}, 146.464^{\circ} \mathrm{W}$ consisted of a single transmitter $(\sim 150 \mathrm{~m}$ up-glacier from $\mathrm{km}-16)$ and two receivers. One (RES16U) was located $80 \mathrm{~m}$ up-glacier from the transmitter. It was a Tektronix 222 oscilloscope recording half-hourly with $20 \mathrm{~ns}$ sampling rate and 128 stacking depth. The other (RES16L) was $80 \mathrm{~m}$ downglacier. It was a Tektronix 2432/2440 recording hourly with $10 \mathrm{~ns}$ sampling rate. Records from RES16U were more complete than those from RES16L, where there were downtimes caused by oscilloscope failure and temporary redirection of the recording system for profiling described above. There were no apparent differences in the overlapping parts of records from $16 \mathrm{U}$ and $16 \mathrm{~L}$, so we present only RES16U (Fig. 5).

With the foregoing information for transmitter and RES16U receiver location and assumption of specular reflection off the bed, the bed reflection was located $\sim 190 \mathrm{~m}$ up-glacier from the km-16 profile. Given the bed cross section (Fig. 4) and the TWTT to the bed at RES16U $(\sim 7.2 \mu \mathrm{s})$, we expect that radar energy was reflected from a position $\sim 130 \mathrm{~m}$ north of the deepest part of the bed.

At RES16U there is a strong bed reflection at $\sim 7.2 \mu \mathrm{s}$ as well as persistent returns at other travel times. Diurnal variations in return are prominent near the surface and are also visible at depth. Peak amplitudes always occurred in the late afternoon, when surface water content in the snow was maximum. The strength of diurnal variation was relatively constant at RES16U until day 175, when a slush swamp started to build up around and under the equipment. The abrupt decrease in reflection strength on day 179 coincided with a slushflow, which rapidly drained the water from this region. Thereafter, the equipment was on bare ice. Apart from these diurnal variations, there is no obvious change in the displayed amplitude and timing of reflectivity.

Site RES14 was at $63.482^{\circ} \mathrm{N}, 146.502^{\circ} \mathrm{W}$ on the $\mathrm{km}-14$ profile. There was one transmitter and one receiver (a Fluke 97 oscilloscope recording half-hourly with a 20 ns sampling rate and 256 stacking depth). There are a total of 634 records of 512 samples each. Based on the cross profile measured at km-14 (Gades, 1998, fig. 4.2, deepest return $\sim 7.6 \mu \mathrm{s}$ ) and the TWTT to the bed at RES14 ( 7.4 $\mu$ s), we expect that radar energy was reflected from a position $\sim 190$ m north of the deepest part of the bed.

Similar to RES16U, there was a strong bed reflection $(\sim 7.4 \mu \mathrm{s})$ and persistent internal returns, with diurnal variations most prominent in the near surface. Unlike RES16, the snowline did not reach RES14 during the observation interval, and there was no time of anomalous diurnal variations associated with a snow swamp. Because of the visual similarity of features to Figure 5 and their availability in Gades (1998, fig. 5.4), they are not shown here. They are analyzed below.

\section{DATA ANALYSIS}

\subsection{Temporal variations near the center of the glacier}

Changes in reflection from within the ice and at the bed are subtle compared to near-surface effects at the level of display provided in Figure 5. We now undertake analysis to determine what limits on changes in bed reflectivity can be determined at RES16U and RES14. To do this we seek persistent, time-independent internal reflectors that can be used to calibrate and correct for changes in power 


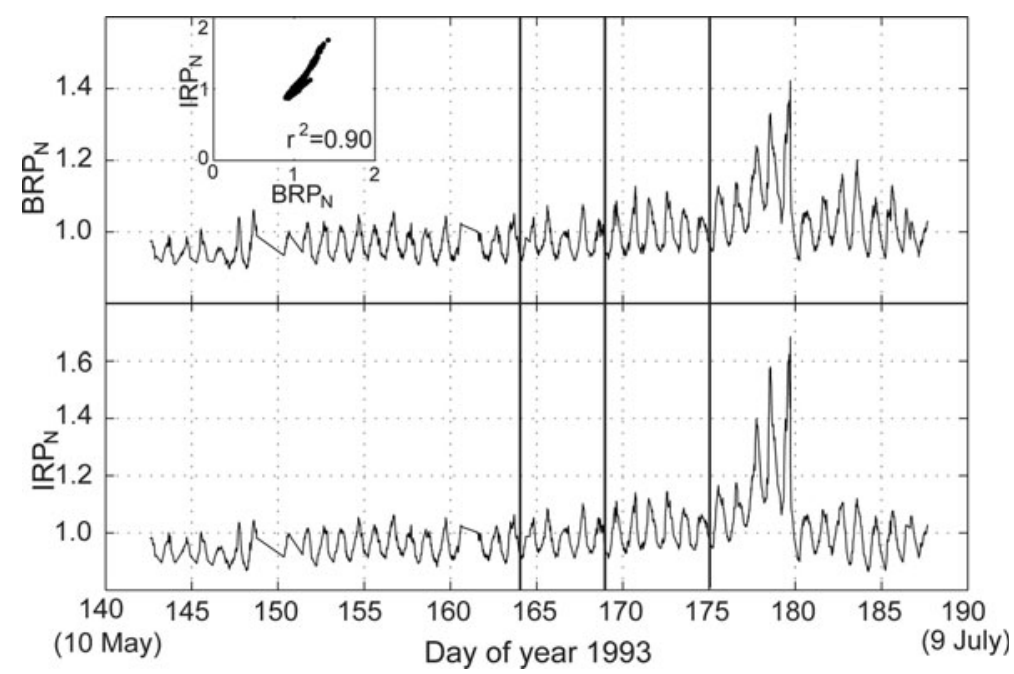

Fig. 6. RES16U normalized reflection power from bed (upper curve) and interior (lower curve) showing a high degree of correlation (inset plot). Vertical lines show times of lake drainage.

transmission through the near surface (Gades, 1998; Kulessa and others, 2008).

For this analysis we define surface, internal and bed zones (Fig. 5) as well as a pre-trigger zone (not shown). To make quantitative comparisons of reflected power from different return-time windows, the returned power $P$ represented by signal samples $A_{i}$ from within a return-time interval $t_{1}-t_{2}$ is defined as the sum of squared samples divided by the number of samples:

$$
P \equiv \frac{1}{\left(n_{2}-n_{1}+1\right)} \sum_{i=n_{1}}^{n_{2}} A_{i}^{2}
$$

where $n_{1}$ and $n_{2}$ are the sample numbers corresponding to $t_{1}$ and $t_{2}$.

To determine a bed reflection power (BRP), the returntime window is centered on the reflected wavelet with length two times its period $T$. A collective internal reflection power (IRP) coming from internal layers and scattering is defined over a return-time window chosen to start after the high-amplitude direct wave with associated signal clipping ( $3 \mu \mathrm{s}$ or later) and to end before the bed reflection ( $7 \mu \mathrm{s}$ or sooner). The first limit successfully eliminates the nearsurface part of the waveform over the complete interval of observations with the exception of days 175-180 at the RES16U site, when amplitudes of diurnal variation were especially high (Fig. 5).

Figure 6 shows variations of BRP and IRP at RES16U, with IRP computed over a uniform time window, 5.5-7 $\mu \mathrm{s}$, to enclose only the deepest scattering. For comparison, BRP and IRP are both normalized by the relation value/mean. $B R P_{N}$ and $I R P_{N}$ show clear (mostly diurnal) variations that are not evident at the level of display in Figure 5. The sizes of these temporal variations are large (up to $40 \%$ ). A linear regression shows that $\mathrm{BRP}$ and IRP are highly (positively) correlated at both RES16U $\left(r^{2}=0.90, N=1700\right)$ and RES14 $\left(r^{2}=0.84, N=640\right)$.

Principal component analysis (Dillon and Goldstein, 1984) provides another way to examine the covariation of features in the RES records. Principal components are formed from linear combinations of $n$ RES records of $m$ samples each to form an orthogonal set of $n$ normalized basis functions $\mathbf{E}_{i}$ that are chosen to sequentially minimize the variance represented in the residual subspace. Any individual RES record (number $r$ in interval 1 to $n$ ) can then be represented as the sum of its projections on the principal components ( $i$ from 1 to $n$ ), the size of which is given by the corresponding coefficients $C_{i r}$ This technique allows us to quantitatively extract patterns in the waveforms that are most consistent through the time history and identify those features that are variable.

Figure $7 \mathrm{a}$ shows a typical record at RES16U for the interval $3-9 \mu$ s. Figure $7 b-d$ show the first three principal components calculated for that sampling sub-interval ( $m=300$ samples) for the full set of RES records $(n=1747)$. Figure $7 \mathrm{e}$ shows the fractions of the total data variance explained by the first ten principal components. The break in slope in the explained variance between the first principal component and the second through tenth components indicates by the so-called scree test (e.g. Dillon and Goldstein, 1984) that only the first component is significant in this case. Effectively, the variation with time of RES records through the full measurement interval can be represented by a single waveform (the first principal component) with varying amplitude $\left(\mathrm{C}_{1 r}\right)$. These results are consistent with the high degree of correlation between variations in IRP and BRP noted above, as well as details of all subsurface features deeper than $3 \mu \mathrm{s}$.

It is compelling to conclude that the proportional changes in IRP and BRP arise from changes in the transmission and reception of the radar power through the upper surface due to varying system (antennas) interaction with it. This conclusion is consistent with the known characteristics of the water variation in the snow and on the ice surface (described above). Note that strongest returns occurred when surface water content was a maximum (late afternoon and persisting slush). Apparently, high water content in the near-surface snow and/or ice significantly enhanced the coupling of the low-frequency antennas to the dielectric interface formed by the air/snow/ice transition.

\subsubsection{Power reflectivity of the bed}

Whatever their causes, strong variations in transmitted and received power through the surface zone must be taken into account to delineate locally induced variations in the 

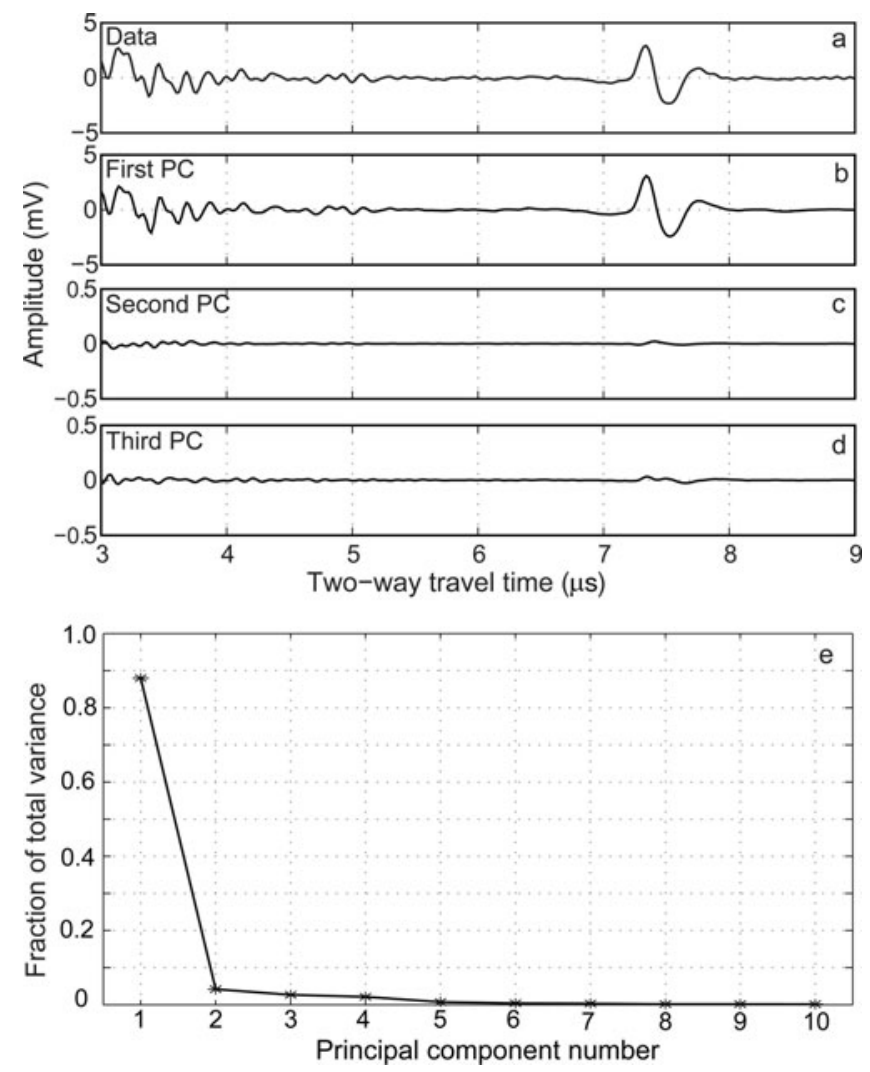

Fig. 7. (a) Example record from RES16U, day 158.6. (b-d) The first three principal components $\mathbf{E}_{1}$ (b), $\mathbf{E}_{2}$ (c) and $\mathbf{E}_{3}$ (d) scaled by their coefficients $C_{1}, C_{2}$ and $C_{3}$ respectively as calculated from the $n=N=1747$ RES records and $m=300$ samples in the shown traveltime interval. (Note the change in vertical scale in (c) and (d) compared to (b).) (e) The fraction of the total variance for the first ten principal components.

scattering strength in the ice and reflectivity of the bed. A measure of the variation in power transmitted into the ice is sought by identifying stable reflection patterns within the interior zone (Fig. 5) well below the near surface. The strongest reflectors/scatterers are likely to be water-filled cavities (e.g. Jacobel and Anderson, 1987). Those cavities, either isolated from the connected internal drainage system or lying beneath the range of water-level fluctuations would have time-independent reflectivity. Wet englacial sediment bodies are other potential stable sources of radar returns. The time-varying amplitude returning from such stable reflectors/scatterers can then be used to calibrate changing interaction of the radar system with the surface zone and travel path through it.

To identify the most stable reflection pattern in the interior zone, the first principal component $\mathbf{E}_{1}$ is calculated for only this zone, in this case chosen to be $3-7 \mu$ s to represent as much of the interior zone as possible without near-surface or bed influence. $\mathbf{E}_{1}$ represents the shape of the most common waveform from the interior throughout the measurements and arises from reflectors that are most constant. In these data the first principal component accounts for $\sim 76 \%$ of the total variance, indicating that most of the returned signal from the interior is, in fact, due to persistent features.

The amplitude of $\mathbf{E}_{1}$ present in the $i$ th waveform, represented as $C_{1 i}$, is calculated by projecting the $i$ th waveform onto the normalized vector $\mathbf{E}_{1}$. $C_{1 i}$ then represents the amplitude of the signal from the most persistent internal reflectors.

A linear relationship between $C_{1 i}$ and the corresponding measured $\mathrm{BRP}_{i}$ would indicate a covariation caused only by varying amounts of radar power reaching the ice subsurface (because of instrumentation and/or ice surface property variations), which would proportionally affect BRP and timeindependent scatterers. A residual BRP is defined as

$$
\mathrm{BRP}_{\mathrm{R}}=\mathrm{BRP}-\left(A+B C_{1}\right)
$$

where $A$ and $B$ are coefficients determined by the leastsquares linear fit between $C_{1 i}$ and $\mathrm{BRP}_{i}$. Non-zero $\mathrm{BRP}_{\mathrm{R}}$ is then due to variations in the physical conditions at the base of the glacier or error.

Error in each $\mathrm{BRP}_{\mathrm{R} i}$ defined by Eqn (2) comes from instrumentation and environmental noise. A standard error in $\mathrm{BRP}_{i}$ (Eqn (1)) was estimated based on the pre-trigger data noise level in the ith record. The error in $C_{1 i}$ depends on the number of interior-zone samples, $m$, chosen for the analysis and noise level in the ensemble of waveforms as well as in the ith waveform. The dependence of standard error in $C_{1 i}$ on $m$ and noise levels was estimated empirically using a series of tests on a known set of $n$ waveforms generated from a representative measured waveform with added Gaussian white noise of distribution and amplitude range characteristic of the background pre-trigger sampling interval (Gades, 1998).

Results for $\mathrm{BRP}_{\mathrm{R}}$ in Figure 8 show that it is less than about $\pm 5 \%$ of the mean BRP. At RES16U, the linear least-squares best fit for $\mathrm{BRP}_{\mathrm{R}}$ over time suggests a declining trend in amplitude of only $\sim 3.2 \%$ with root-mean-square $(\mathrm{rms})$ error of $4 \%$ over the measurement period. The corresponding values are amplitude of $2.2 \%$ with rms error of $5 \%$ at RES14. Evidently, any actual temporal variations in bed reflectivity must be less than $\pm 5 \%$ throughout the record time-span at both km-14 and km-16. Uncertainty in $\mathrm{BRP}_{\mathrm{R}}$ (error bars in Fig. 8) indicates that any actual variations of $\pm 5 \%$ or less cannot be discriminated with confidence. In any case, the suggested low-level fluctuations and trends (Fig. 8) are not clearly correlated with changes in speed (Fig. 3).

\subsubsection{Bed reflection phase}

Figure 9 shows the zero lag correlation of the bed reflection pulse relative to the mean reflection pulse using the fixed time window centered on the mean pulse. The extremely high degree of correlation $(\sim 0.99)$ at both RES14 (Fig. 9a) and RES16U (Fig. 9b) indicates that the reflected pulse timing and shape were nearly constant over the measurement period at both sites.

An immediate conclusion of the consistency of the bed return pulse is that there are strong limits on changes in the transmitted pulse, ice thickness, mean wave speed through the ice and phase spectrum of the bed reflectivity. The first three are expected from our instrumentation, the consistent timing of returns and the correlations in amplitude of power returns discussed above. To quantify limits on changes in phase of the bed reflection, Figure 10 shows the phase spectra of the mean pulse and the least correlated pulse at RES16U calculated using the discrete Fourier transform. The phase difference is $<0.01 \mathrm{rad}$ for the pulse center frequency $(\sim 2.2 \mathrm{MHz})$ and $<0.05 \mathrm{rad}$ over the full frequency range of usable power return $(\sim 1$ to $\sim 5 \mathrm{MHz})$. Results are similar at RES14. The implication is that changes in the phase of bed reflection are $<0.05 \mathrm{rad}$. 


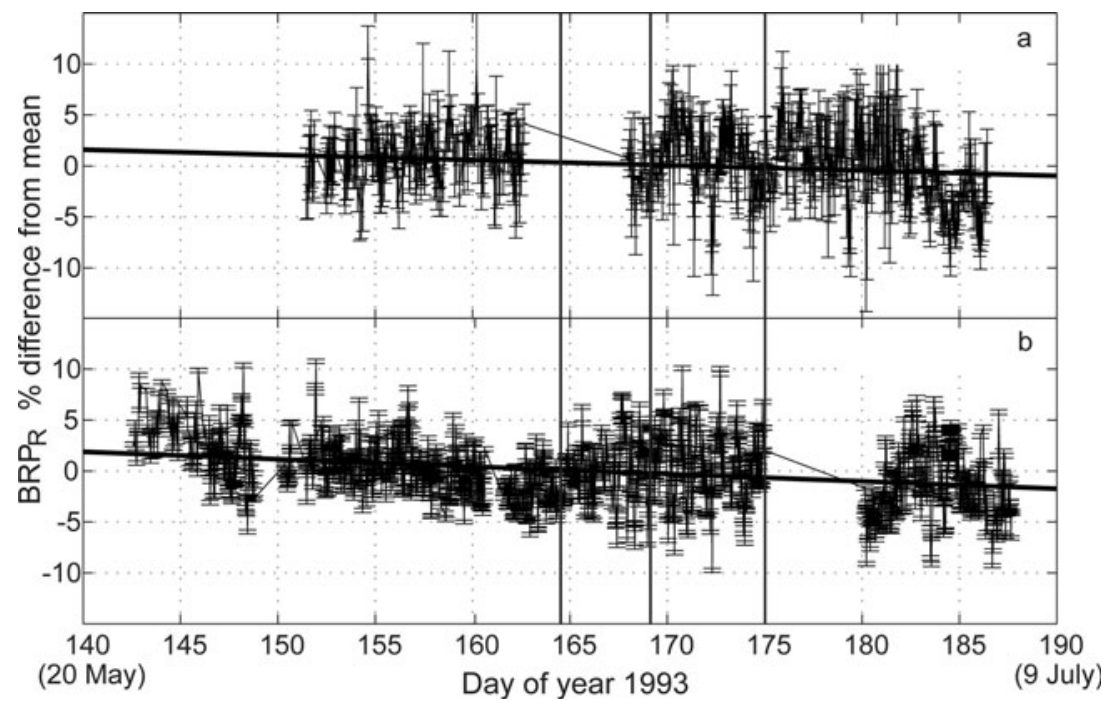

Fig. 8. Residual bed reflection power $\left(\mathrm{BRP}_{\mathrm{R}}\right.$, Eqn (2)) for RES14 (a) and RES16U (b). Values and standard error are plotted as a percentage difference from the mean. Vertical lines show times of lake drainage.

\subsection{Temporal variations along cross profiles}

A similar path of analysis to that developed in Section 4.1 was followed to account for changes in instrumental and surface conditions at the 13 fixed measurement locations on the cross profiles (Figs 2 and 4). Results for $\mathrm{BRP}_{\mathrm{R}}$ (Eqn (2)) are shown in Figure 11. The only difference in method was calculation of bed return power as the peak-to-peak amplitude of the pulse squared (linearly related to BRP from Eqn (1) as verified empirically using the data from RES16U where consistency of the bottom pulse permits comparison). This evaluation was motivated because sampling over the full length of the bed reflection pulse was less clear at some locations and times (partly due to the lower power of $5 \mathrm{MHz}$ antennas).

Uncertainties are larger than those found at RES16U and 14. In addition to a less well-defined bed reflection, there are other factors associated with identifying stable internal reflectors: a much smaller number of records (4-6 compared to 640-1700); smaller ice thickness at most locations, with correspondingly smaller interior region (e.g. along km-16 (Fig. 4)); and imperfect repositioning at markers, compromising exact duplication of the distribution of internal

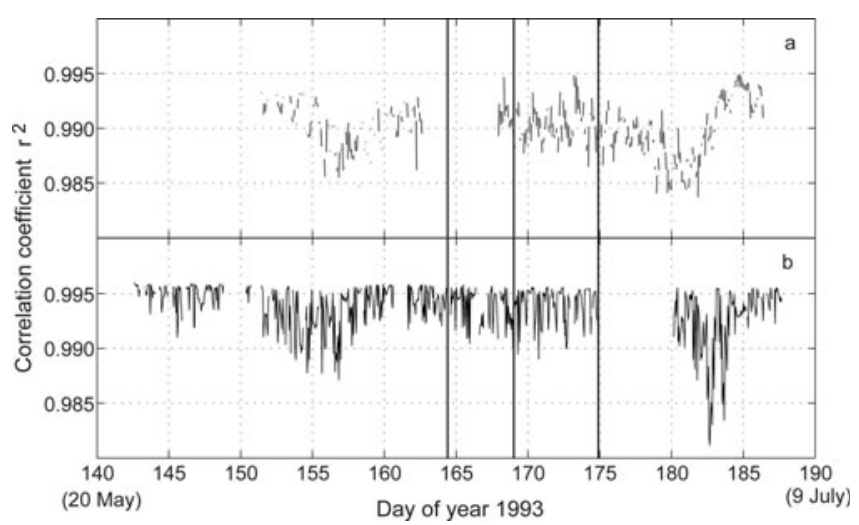

Fig. 9. RES14 (a) and RES16U (b) zero lag correlation of bed reflection pulse with the mean pulse for hourly measurements. Vertical lines show times of lake drainage. reflectors. As a result, the first principal component $\mathbf{E}_{1}$ of the interior zone describes a smaller fraction of the total data variance. Uncertainty along $\mathrm{km}-18$ was especially large $\left(\mathbf{E}_{1}\right.$ accounting for $<40 \%$ of variance), where difficult snow conditions reduced access to four measurements. At km-14 and $\mathrm{km}-16$, results were generally better defined $\left(\mathbf{E}_{1}\right.$ accounting for $>60 \%$ of variance).

Locations along the km-14 and km-16 lines show that change in $\mathrm{BRP}_{\mathrm{R}}$ in the central portion of the glacier was below a detection limit of about $\pm 10 \%$. This is consistent with results from RES14 and RES16U near the center, which impose even smaller limits on change.

In contrast, changes in $\mathrm{BRP}_{\mathrm{R}}$ can be recognized at five locations, all away from the center: km-14-1104 m showed upward shifts of about $35-50 \%$ on days 158.45 and 175.45 ; $\mathrm{km}-16-840 \mathrm{~m}$ and $+514 \mathrm{~m}$ showed temporary highs on day 166.5; km-16-663 m showed a temporary high on day 171.55; and km-16+324 m showed an upward jump ( $\sim 60 \%$ ) on day 161.45 .

Although $\mathrm{km}-14-1104 \mathrm{~m}$ and $\mathrm{km}-16+324 \mathrm{~m}$ suggest an increase in reflectivity over the sampling interval, a coherent

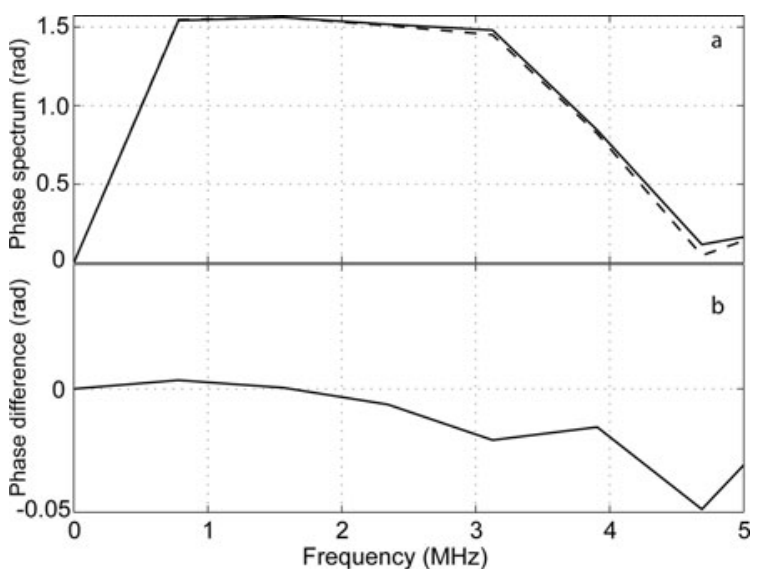

Fig. 10. (a) Phase spectrum of mean record (solid curve) and least correlated record (day 182.8, dashed curve) from RES16U. (b) Phase difference between the mean record and record from day 182.8 . 


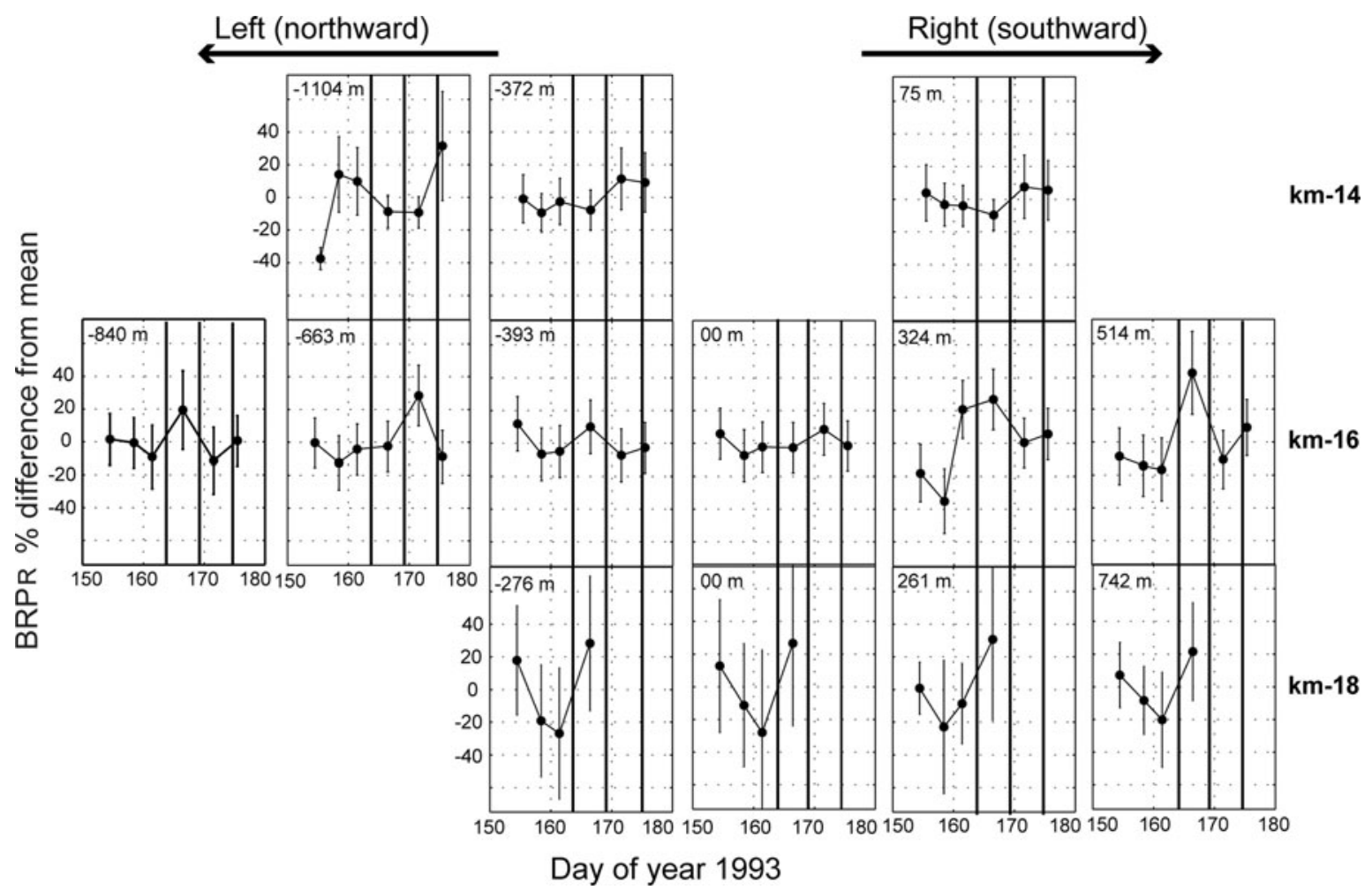

Fig. 11. Residual bed reflection power $\left(B_{R P}\right.$, Eqn (2)) at the poles along profiles km-14, km-16 and km-18 (from top to bottom) ordered left to right as if looking down-glacier. Values and uncertainties are plotted as percentage difference from the mean. Measurement positions (Fig. 2) are given in meters south of glacier center. km-14 and km-16 measurements were made on days 154.5, 158.5, 161.5, 166.5, 171.6 and 175.5. km-18 measurements were made on the first four of those days. Vertical lines show times of lake drainage.

pattern of seasonal change is not obvious. Instead, there are shifts suggesting isolated events. There is no clear one-onone relationship with lake drainage, but an association could be possible if lags are involved.

Nolan and Echelmeyer (1999a, fig. 10) defined a sequence of three periods of anomalous seismic reflection related to the three lake drainages. Radar observation days $154.5,158.45$ and 161.45 preceded any anomalous seismic reflections. Days 166.5 and 171.55 were during anomalies I and II. Day 175.45 was close to the end of anomaly III. There is no clear correlation of radar observation with these seismically anomalous or non-anomalous times. It is noteworthy that no large radar changes were found at km16-393 m, which was close to UAF N1 where the most pronounced seismic anomalies are thought to have been centered (Nolan and Echelmeyer, 1999a).

Unfortunately, the time sampling is not dense enough to explore a correlation between $\mathrm{BRP}_{\mathrm{R}}$ and short-term dynamic events (Fig. 3). The spatial sampling does show that changes in bed reflectivity occurred away from the center, and may have been restricted to non-center locations during the interval of observation.

In view of the clear difficulties of detecting changes at fixed locations, it is not surprising that it is even more problematic to draw conclusions about changes in bed reflectivity from records taken while in motion during profiling. The data quality for detecting temporal changes is lower for reasons stated earlier. The records do not have the degree of correlation needed for the above kind of analysis. Quantification of changes may be possible with a more complex integrated temporal-spatial analysis, which is beyond the scope of this paper.

\section{SYNTHESIS OF BED CONDITIONS}

\subsection{Spatial context}

We focus discussion on $\mathrm{km}-16$, where most data from our radar and UAF studies were concentrated (Fig. 4). Truffer and others (1999) suspect that D1 and N1 are in the Denali Fault zone with different rock terranes to the north and south. The seasonal transfer of basal shear stress from north to south and generally higher stress in the south found by Amundson and others (2006) indicate significant mechanical differences that could be associated with a cross-glacier transition in basal zone composition and/or structure near D1 (Fig. 4). The cross-valley topography radar profiling reveals some asymmetry, with lower slope on the left (north) compared to the right side. The right side shows reflections from longitudinal off-profile variations in topography along the valley's south side. (km-14 shows similar asymmetry (Gades, 1998, fig. 4.2); km-18 (Gades, 1998, fig. 4.4) is more symmetric.)

We are concerned here primarily with spatial variations in reflections from the bed. There are four bright patches $\sim 100 \mathrm{~m}$ wide in the central parts of the profile (deeper than $\sim 5 \mu \mathrm{s}$, roughly between -600 and $+400 \mathrm{~m}$ ). One is in the center. The other three are on the left (north) side of the glacier centered at approximately $-550,-350$ and $-150 \mathrm{~m}$. Amplitudes of bed returns exceed $100 \%$ above the background trend associated with varying travel time. These four bright patches stand out in the profiles from all available times. Farther from the center, the strength of returns is heterogeneous on both sides.

Both N1 and D1 are associated with bright patches. These are locations where till has been detected seismically (Nolan 
and Echelmeyer, 1999a) and directly sampled in UAF boreholes (Nolan and Echelmeyer, 1999a; Truffer and others, 1999) (7 m thick at N1 and $4.5 \mathrm{~m}$ thick at D1). As discussed below, till can be highly reflective compared to most bare rock. Thus, especially reflective till may contribute to the relative brightness at these two locations, with the caution that focusing associated with the concaveupward bed at D1 must also make a contribution here.

We keep in mind that the presence of till has not been demonstrated directly at any locations other than N1 and D1 including the other UAF boreholes, where sub-ice sampling was not done (Nolan and Echelmeyer, 1999a; Truffer and others, 1999). We suspect the presence of highly reflective till at other bright spots, and also suggest that the till cover is not homogeneous or necessarily pervasive given the substantial variability in brightness.

\subsection{Temporal variations of basal water}

We now examine two related questions about temporal changes in bed reflectivity:

1. What are the limits to changes in water at central locations where bed reflectivity changed by $<5 \%$ ?

2. How big must the changes in water be to enable changes of order $50 \%$ in reflectivity similar to those observed at some off-center sites?

Actual mean thicknesses of water on extensive areas of glacier beds are not well known for either hard or soft beds, but are estimated to be in the range $10^{-3}$ to $10^{-1} \mathrm{~m}$ based on observations of surface uplift driven by basal water storage changes, local observations in boreholes and theoretical considerations of water flow and mechanical equilibrium (Fountain and Walder, 1998). Exceptions are localized concentrated flow channels and subglacial lakes. Electrical conductivity of water in the 1993 summer outflow of BRG had mean $\sim 3 \times 10^{-3} \mathrm{~S} \mathrm{~m}^{-1}$ and maximum $\sim 8 \times 10^{-3} \mathrm{~S} \mathrm{~m}^{-1}$ (Raymond and others, 1995). We focus on ranges of water thickness $d$ up to $0.1 \mathrm{~m}$ and electrical conductivity $\sigma$ up to $10^{-2} \mathrm{~S} \mathrm{~m}^{-1}$.

In broad form, bed morphology involves ice, water of varying $d$ and $\sigma$ and substrate of rock or till-on-rock. A substrate permittivity range from about 7 (dry rock) to 25 (high-porosity, water-saturated till) is relevant. A related range of substrate electrical conductivity is $10^{-5}$ to $10^{-4} \mathrm{~S} \mathrm{~m}^{-1}$ (dry rock) to $10^{-3}$ to $10^{-2} \mathrm{~S} \mathrm{~m}^{-1}$ (highly conductive till). These ranges are based on the dielectric properties of water and rock materials, mixing models (Looyenga, 1965) and empirical data (Keller and Frischknecht, 1966) as discussed by Gades (1998). With the foregoing context we consider both rock and till substrates. For practicality, we do not explicitly explore a range of till thicknesses over rock, although important implications are mentioned below. Nor do we consider stratified till including the possible presence of ice in pores, as found by Truffer and others (1999).

We examine a three-layer model (Mclntyre and Aspnes, 1971; Born and Wolf, 1980; Gades, 1998) of ice on a substrate with an intervening water layer of electrical conductivity $\sigma$ and uniform thickness $d$ approximating irregular water patches and passageways (Mclntyre and Aspnes, 1971; Chan and Marton, 1974).

As a reference baseline, we first assume a non-conducting substrate, which enables simple analysis. When the water layer is thin compared to the radar wavelength in it
( $~ 6.4 \mathrm{~m}$ for $5 \mathrm{MHz}$, larger for $2 \mathrm{MHz}$ ) and to the skin thickness beyond which the substrate becomes invisible ( $\sim 5 \mathrm{~m}$ in water with $\sigma \approx 5 \times 10^{-3} \mathrm{~S} \mathrm{~m}^{-1}$ for $2-5 \mathrm{MHz}$ ), the full theory can be approximated by a linearized thin-film theory (Mclntyre and Aspnes, 1971, eqn (28)) in the form

$$
R(\sigma d)=R_{0}\left(1+F_{0} \sigma d\right)
$$

where $R$ is power reflectivity, $R_{0}$ is the background $R$ in the absence of the layer and $F_{0}$ is a constant. Both $R_{0}$ and $F_{0}$ depend only on the properties of the ice and substrate. Change in $R$ caused by the water layer is proportional to $\sigma d$, which represents the layer-parallel conductance per unit width of the layer.

As the permittivity contrast between ice and substrate increases: $R_{0}$ increases; $F_{0}$ decreases; and $R_{0} F_{0}$ varies only weakly over the relevant range of substrate permittivity, 7-25. $R_{0} F_{0} \sigma d$ gives the absolute effect of a water layer, which has a corresponding weak dependence on substrate permittivity. $F_{0} \sigma d$ gives the fractional change in $R$ caused by the layer in comparison to its absence. It declines with increasing substrate permittivity.

Rearranging Eqn (3) gives the sensitivity of the fractional change in $R$ to a change in $\Delta(\sigma d)$ from an initial condition $\sigma d$ as

$$
\frac{\Delta R}{R}=\frac{F_{0}}{1+f_{0} \sigma d} \Delta(\sigma d)
$$

Because of the dependence on $\sigma d$, sensitivity to the amount of water $d$ is higher when $\sigma$ is relatively large. Correspondingly, when $d$ is large, sensitivity to $\sigma$ is enhanced.

We first consider a substrate of permittivity 8 (e.g. dry rock). Figure 12 shows both $R$ (solid curves) and phase $P$ (dashed curves) calculated from the full model depending on water thickness $d$ (up to $0.1 \mathrm{~m}$ ) and electrical conductivity $\sigma$ (up to $10^{-2} \mathrm{~S} \mathrm{~m}^{-1}$ ). Starting from the assumed bed with no water layer $(R=0.052)$, fractional change in $R$ approaching 6 can be achieved in the displayed range of $d$ and $\sigma$. With reference to the linearized approximation $R_{0}=0.052$, $F_{0}=6.2 \times 10^{3} \mathrm{~S}^{-1}, R_{0} F_{0}=0.32 \times 10^{3} \mathrm{~S}^{-1}$, and Eqn (3) gives a close approximation to power reflectivity shown in Figure 12.

The pattern of $R$ calculated for a substrate permittivity of 25 (e.g. possibly realized by wet porous till with clean porewater) looks closely similar to Figure 12 for permittivity 8 . The difference is the addition of $\sim 0.18$ to each $R$ contour value, which accounts for a higher bare substrate reflectivity of 0.23 compared to 0.05 . The fractional change in $R$ across the range is $\sim 1.4$ compared to 6.2 , so sensitivity is lower by a factor of $\sim 4.4$. The linearized approximation (Eqn (3)) is given by $R_{0}=0.23, F_{0}=1.4 \times 10^{3} \mathrm{~S}^{-1}$ and $R_{0} F_{0}=0.31 \times 10^{3} \mathrm{~S}^{-1}$.

Figure 13 shows the changes in $\sigma d$ required for $\Delta R / R$ of less than $0.05(5 \%)$ and more than 0.50 (50\%) depending on the initial $\sigma d$ based on Eqn (4). The loss in sensitivity going from substrate permittivity 8 (heavy lines) to 25 (light lines) is evident. However, in either case and through the intervening range of permittivity, $50 \%$ changes in $R$ can be produced by changes in $\sigma d$ within the expectations of reasonable variation. Correspondingly, changes in $R$ less than $5 \%$ restrict changes in $\sigma d$ to be a small fraction of the range.

For specific illustration, consider a constant $\sigma=3 \times$ $10^{-3} \mathrm{~S} \mathrm{~m}^{-1}$ (the stream outflow average in summer) and a range of initial $d$ of $0.00-0.10 \mathrm{~m}$. To obtain $\Delta R / R>0.5, \Delta d$ 


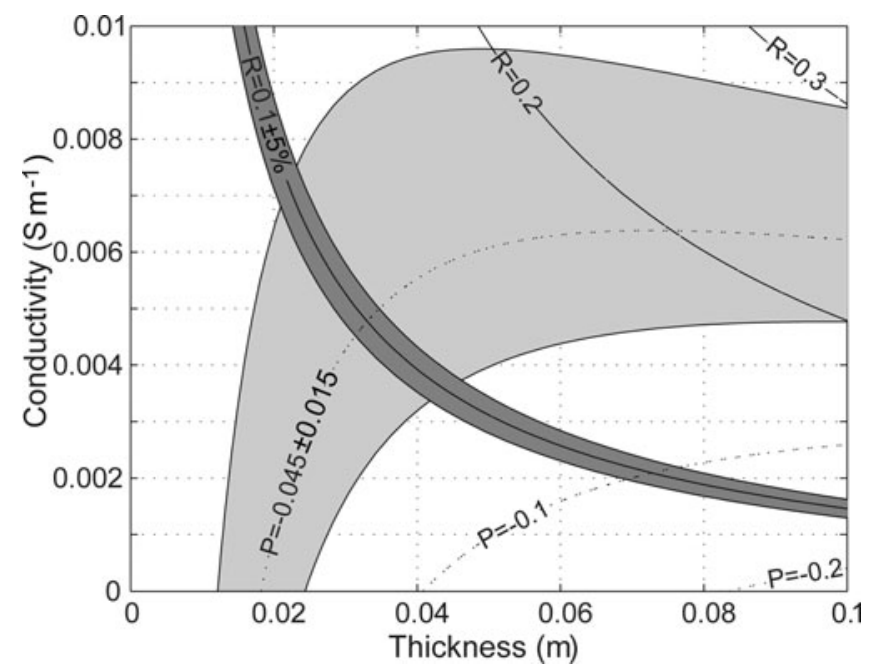

Fig. 12. Contours of power reflectivity $R$ (solid lines; interval 0.1 ) and phase $P$ (dashed lines; radians interval 0.1 ) for $2 \mathrm{MHz}$ wave impinging on a water layer of given thickness and conductivity situated between ice (permittivity 3.17) and solid rock of assumed real permittivity 8 (intermediate between 7 for limestone and 11 for basalt (Jones, 1987)). Power reflectivity with no water layer (0 thickness) is 0.052 . Dark-gray region shows power reflectivity of $0.1 \pm 0.05$ ( $\pm 5 \%$ ). Light-gray region shows phase of $-0.045 \pm 0.015$ rad, which is the maximum variation expected for $2 \mathrm{MHz}$ center frequency (Fig. 10). The area in common between the gray regions is the allowable combined variation in water-layer thickness and conductivity for the specified set of initial conditions (in this case, $R=0.1$ and $P=0.045$.

would have to be more than $0.027-0.077 \mathrm{~m}$ for permittivity 8 , or $0.122-0.172 \mathrm{~m}$ for permittivity 25 . To restrict $\Delta R / R$ to $<0.05, \Delta d$ would have to be less than $0.0027-0.0077 \mathrm{~m}$ for permittivity 8, or $0.012-0.017 \mathrm{~m}$ for permittivity 25 .

When emphasis is on detecting changes in the amount of water $d$, the co-effect of $\sigma$ prevents unique interpretation unless $\sigma$ can be constrained. For example, adding relatively clean water to the base could just dilute ionic solutes and leave $\sigma d$ and $R$ unchanged (not probable, but conceivable). Phase information can help limit this ambiguity, since its dependence on $d$ and $\sigma$ can have a different pattern (e.g. Fig. 12, light filled region).

With this three-layer morphology and typical $\sigma$ summer water: (1) fractional changes in power reflection of $<5 \%$ are quite restrictive to changes in $d$ at the sub-cm level for low bed permittivity and a few centimeters at high permittivity; (2) fractional changes in power reflection of $50 \%$ are quite possible with glaciologically reasonable changes in $d$ of $<10 \mathrm{~cm}$ to a few tens of centimeters. The difference between near-center and off-center reflection changes would indicate more active hydrological changes away from the center.

Consideration of electrical conductivity in the substrate presents a substantial difficulty for conclusions about (1) and (2). Based on the empirical formula of Keller and Frishknecht (1966), till with high porosity (0.4) saturated with conductive water like the minimum for summer outflow, $\sigma=8 \times 10^{-3} \mathrm{~S} \mathrm{~m}^{-1}$, would have a bulk conductivity $\sigma=3 \times 10^{-3} \mathrm{~S} \mathrm{~m}^{-1}$ (like the mean summer outflow). Even higher pore-water conductivity and correspondingly higher bulk till conductivity could be possible given the relatively long residence time in contact with rock of pore-water in till compared to through-flowing meltwater.

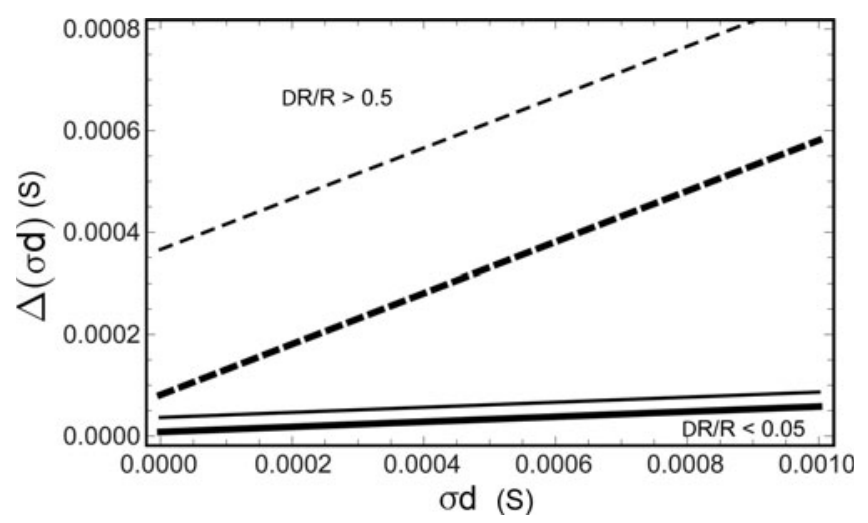

Fig. 13. Upper limit on changes in $\sigma d$ for $\Delta R / R \leq 0.05$ (solid lines), and lower limit on changes in $\sigma d$ for $\Delta R / R \geq 0.50$ (dashed lines) for permittivity 8 (heavy) and 25 (light).

We have not found a simple analytical description of the relationship of $R$ to $d$ and $\sigma$ for a water layer on a conductive bed. The relevant basic features derived from the full model are nevertheless simply described for the high end of the range. When conductivity for the substrate is similar to or higher than $\sigma=3 \times 10^{-3} \mathrm{~S} \mathrm{~m}^{-1}, R$ of the substrate alone can exceed 0.5. Correspondingly, $R$ varies $<0.2$ in the full reference ranges of $d$ up to $0.1 \mathrm{~m}$ and $\sigma$ up to $10^{-2} \mathrm{~S} \mathrm{~m}^{-1}$ and phase varies by $<0.1 \mathrm{rad}$. When water-layer and substrate conductivity are similar, there is a loss of sensitivity to changes in $d$. When $\sigma$ of the water layer is less than substrate conductivity, $R$ decreases (weakly) with increasing $d$. If substrate conductivity were this high over a thickness of meters, the radar would not detect even modest changes in water. Relative to the above questions: (1) changes in water at the decimeter scale could go undetected even with the $5 \%$ detection level for power reflection; and (2) fractional changes in power reflection of $50 \%$ require exceptionally large changes in water amount of more than a few decimeters.

The detection of changes in some places shows that locally the bed is not mantled with till so thick and conductive as to hide hydrological influence on reflections. Indeed, very high-porosity, dilated till is likely to be restricted to a thin layer on top of or in till that is partially consolidated and possibly stratified (Truffer and Harrison, 2006). Known full till thickness of 4-7 m cannot be considered either thick (obscuring underlying rock) or thin (much thinner than the wavelength, $\sim 12 \mathrm{~m}$ for $5 \mathrm{MHz}$ in high-porosity till), allowing interference of reflections from the top and bottom interfaces with large changes in reflectivity over quarter-wavelength changes in thickness. A spectrum of substrate reflection characteristics between bare rock and thick conducting till can be expected (Gades, 1998), with corresponding ambiguity for answering (1) and (2).

From this perspective, the difference in the central band of temporally constant reflectivity compared with variable locations to the side could have more to do with differences in bed morphology than hydrological driving. Away from the central zone, there are locations not mantled with till so thick and conductive as to hide hydrological effect on reflections, and changes in water amount are $10 \mathrm{~cm}$ or larger if significant till is present. In the central zone, UAF boreholes show till is very likely at radar measurement points, but without information about its electrical properties it is 
difficult to place upper limits on changes in the amount of water between till and ice.

In combination we conclude that the center and much of the north side of the glacier is probably mantled by conductive till over which hydrological activity is not visible with our low-frequency radar methods, and that there are local places on both sides, perhaps more pervasively in the south, where the bed is both morphologically different and hydrologically active.

\subsection{Changes in till structure}

A relevant question is the role of changes in the till itself induced by normal and shear stress fluctuations forced by water and ice acting on its upper surface. Diffusion of porewater through till can affect seasonal change in speed (Truffer and others, 2001). Low hydraulic diffusivity of till limits pore-water change through the full thickness on the sub-daily timescale of lake drainage and motion events, so changes in the till structure are expected to be concentrated in thin zones at the upper surface or possibly inside, involving only local water transfer. On the basis of the foregoing discussion, such changes would be difficult to detect in conductive till.

However, we are motivated to address whether the radar can detect changes in the full thickness of the till proposed to explain the anomalous seismic reflections associated with lake drainages (Nolan and Echelmeyer, 1999b). The central feature is a small dilation of the low-permeablility, normally water-saturated till at nearly constant water content with exsolved gas filling the added void space. An estimate of the upper limit of dilation is 0.02 volume fraction based on uplift of $0.1 \mathrm{~m}$ or less spread over at least $5 \mathrm{~m}$ of till thickness. Linear mixing models (e.g. Looyenga, 1965) indicate an addition of $<0.02$ volume fraction of gas-filled void space causes reduction in permittivity by $<0.1$ to 0.8 for original bulk permittivity of $7-25$. The corresponding fractional reductions in $R$ are 0.03 in either case. These changes are too small to be detected by the radar. Reduction caused by electrical conductivity change would also be small and undetectable on the same basis, noting that high nonlinearity near a percolation threshold would not be expected for a small volume fraction of the insulating gas bubbles. Thus, this kind of change in the till could not be disallowed or confirmed by the radar measurements, even in the central part of the glacier where changes in radar reflection are constrained to be very small. The proposed mechanism to excite dilation is reduction of the normal stress on the top of a significant area of till by local overpressurization of water in a network of passageways. The pressurization itself or modest expansion and thickening of the passageways would also not be visible with the radar.

\section{CONCLUSIONS}

For low-frequency $(2-5 \mathrm{MHz})$ radar, the coupling of surfacedeployed, resistively loaded dipole antennas strengthens with increasing water content of the snow and/or nearsurface weathered ice. An implication is that wet surface conditions are favorable for detecting weak subsurface reflections such as the bed beneath deep ice. A wet surface also increases the amount of direct current induction in the receiving antenna as well as its rate of decay, which is a disadvantage for detecting shallow reflectors, especially if they are weak. Fluctuating surface wetness poses major problems for monitoring temporal changes in internal and bed reflectivity at any depth. It is possible to correct for varying antennas coupling and other system variations by identifying consistent internal reflectors that can be used for relative calibration of the system and antenna coupling. Principal component analysis provides one such means.

On BRG, below the near-surface zone, there was a high degree of spatial correlation of internal scattering and bed reflectivity, indicating a very stable dielectric structure both internal and at the bed with undetected influence from variable water content or conductivity. Time-independent travel times and corresponding constancy of radar wave velocity also indicate that changes in internal water storage must be small or local.

In the deepest part of the glacier cross section, bed reflectivity varied by less than $5 \%$ in power and 0.05 rad in phase through the spring speed-up and summer slowdown and related motion events induced by lake drainages. In contrast, changes in bed reflectivity of up to $50 \%$ were identified at some locations away from the center.

Theoretical analyses indicate that changes in reflectivity from a rock bed of $<5 \%$ constrain equivalent basal waterlayer thickness changes to centimeter scale or less. The presence of conductive till at the bed degrades the tightness of constraint to decimeter scale or more. Changes in bed reflectivity of up to $50 \%$ suggest that there was probably not thick conductive till in those locations, and the changes were caused by centimeter to decimeter changes in water thickness.

The cross-profile topography and reflection brightness together with locations of identified reflection variability suggest that the till cover is widespread, but not homogeneous or necessarily pervasive.

The widespread presence of till, especially under the central locations chosen for high-time-resolution monitoring, prevented detection of changes in basal hydrology and timing in relation to lake drainages and glacier speed changes.

The presence of highly reflective basal till will generally challenge the combined spatial/temporal detection of subdecimeter changes in basal water thickness under thick temperate ice with radar methods.

\section{ACKNOWLEDGEMENTS}

This project was supported by US National Science Foundation (NSF) grant Nos. OPP-9122540 and OPP0520541 to the University of Washington. Support to the University of Alaska by NSF grant No. OPP-9122783, and the resulting collaboration with $\mathrm{K}$. Echelmeyer, M. Nolan and C. Larsen was essential for successful execution of the fieldwork. Martin Truffer provided considerable help in establishing the locations of our measurements relative to subsequent measurements by UAF. Three reviewers prompted improvement in presentation and balance of the manuscript.

\section{REFERENCES}

Amundson JM, Truffer M and Lüthi MP (2006) Time-dependent basal stress conditions beneath Black Rapids Glacier, Alaska, USA, inferred from measurements of ice deformation and surface motion. J. Glaciol., 52(178), 347-357 (doi: 10.3189/ 172756506781828593) 
Bartholomaus TC, Anderson RS and Anderson SP (2008) Response of glacier basal motion to transient water storage. Nature Geosci., 1(1), 33-37 (doi: 10.1038/ngeo.2007.52)

Born M and Wolf E (1980) Principles of optics: electromagnetic theory of propagation interference and diffraction of light, 6th edn. Pergamon Press, London

Bradford JH, Nichols J, Mikesell TD and Harper JT (2009) Continuous profiles of electromagnetic wave velocity and water content in glaciers: an example from Bench Glacier, Alaska, USA. Ann. Glaciol., 50(51), 1-9 (doi: 10.3189/172756409789097540)

Chan EC and Marton JP (1974) Generalized Maxwell Garnett equations for rough surfaces. J. Appl. Phys., 45(11), 5004-5007 (doi: 10.1063/1.1663173)

Cuffey KM and Paterson WSB (2010) The physics of glaciers, 4th edn. Butterworth-Heinemann, Oxford

Dillon WR and Goldstein M (1984) Multivariate analysis methods and applications. Wiley, New York

Fountain AG and Walder JS (1998) Water flow through temperate glaciers. Rev. Geophys., 36(3), 299-328

Gades AM (1998) Spatial and temporal variations of basal conditions beneath glaciers and ice sheets inferred from radio echo soundings. (PhD thesis, University of Washington)

Harrison WD, Mayo LR and Trabant DC (1973) Temperature measurements of Black Rapids Glacier, Alaska, 1973. In Weller $\mathrm{G}$ and Bowling SA eds. Climate of the Arctic: Proceedings of 24th Alaska Science Conference. Geophysical Institute, University of Alaska, Fairbanks, AK, 350-352

Heinrichs TA, Mayo LR, Echelmeyer KA and Harrison WD (1996) Quiescent-phase evolution of a surge-type glacier: Black Rapids Glacier, Alaska, U.S.A. J. Glaciol., 42(140), 110-122

Irvine-Fynn TDL, Moorman BJ, Williams JLM and Walter FSA (2006) Seasonal changes in ground-penetrating radar signature observed at a polythermal glacier, Bylot Island, Canada. Earth Surf. Process. Landf., 31(7), 892-909 (doi: 10.1002/esp.1299)

Jacobel RW and Anderson SK (1987) Interpretation of radio-echo returns from internal water bodies in Variegated Glacier, Alaska, U.S.A. J. Glaciol., 33(115), 319-323

Jones FHM (1987) Digital impulse radar for glaciology: instrumentation, modelling and field studies. (MSc thesis, University of British Columbia)

Keller GV and Frischknecht FC (1966) Electrical methods in geophysical prospecting. Pergamon Press, New York

Kulessa B, Booth AD, Hobbs A and Hubbard AL (2008) Automated monitoring of subglacial hydrological processes with groundpenetrating radar (GPR) at high temporal resolution: scope and potential pitfalls. Geophys. Res. Lett., 35(24), L24502 (doi: 10.1029/2008GL035855)

Looyenga H (1965) Dielectric constant of heterogeneous mixtures. Physica, 31(3), 401-406
Mair D, Willis I, Fischer UH, Hubbard B, Nienow P and Hubbard A (2003) Hydrological controls on patterns of surface, internal and basal motion during three 'spring events': Haut Glacier d'Arolla, Switzerland. J. Glaciol., 49(167), 555-567 (doi: 10.3189/ 172756503781830467)

McIntyre JDE and Aspnes DE (1971) Differential reflection spectroscopy of very thin surface films. Surf. Sci., 24(2), 417-434

Murray T, Booth A and Rippin DM (2007) Water-content of glacierice: limitations on estimates from velocity analysis of surface ground-penetrating radar surveys. J. Environ. Eng. Geophys. 12(1), 87-99 (doi: 10.2113/JEEG12.1.87)

Nolan M and Echelmeyer K (1999a) Seismic detection of transient changes beneath Black Rapids Glacier, Alaska, U.S.A.: I. Techniques and observations. J. Glaciol., 45(149), 119-131

Nolan M and Echelmeyer K (1999b) Seismic detection of transient changes beneath Black Rapids Glacier, Alaska, U.S.A.: II. Basal morphology and processes. J. Glaciol., 45(149), 132-146

Post AS (1960) The exceptional advances of the Muldrow, Black Rapids, and Susitna Glaciers. J. Geophys. Res., 65(11), 3703-3712

Raymond CF, Benedict RJ, Harrison WD, Echelmeyer KA and Sturm M (1995) Hydrological discharges and motion of Fels and Black Rapids Glaciers, Alaska, U.S.A.: implications for the structure of their drainage systems. J. Glaciol., 41(138), 290-304

Truffer $M$ and Harrison WD (2006) In situ measurements of till deformation and water pressure. J. Glaciol., 52(177), 175-182 (doi: 10.3189/172756506781828700)

Truffer M, Motyka RJ, Harrison WD, Echelmeyer KA, Fisk B and Tulaczyk S (1999) Subglacial drilling at Black Rapids Glacier, Alaska, U.S.A.: drilling method and sample descriptions. J. Glaciol., 45(151), 495-505

Truffer M, Harrison WD and Echelmeyer KA (2000) Glacier motion dominated by processes deep in underlying till. J. Glaciol., 46(153), 213-221 (doi: 10.3189/172756500781832909)

Truffer M, Echelmeyer KA and Harrison WD (2001) Implications of till deformation on glacier dynamics. J. Glaciol., 47(156), 123134 (doi: 10.3189/172756501781832449)

Truffer M, Harrison WD and March RS (2005) Correspondence. Record negative glacier balances and low velocities during the 2004 heatwave in Alaska, USA: implications for the interpretation of observations by Zwally and others in Greenland. J. Glaciol., 51(175), 663-664 (doi: 10.3189/ 172756505781829016)

Walford MER and Kennett MI (1989) A synthetic-aperture radioecho experiment at Storglaciären, Sweden. J. Glaciol., 35(119), 43-47

Weertman BR (1993) Interpretation of ice sheet stratigraphy: a radio-echo sounding study of the Dyer Plateau, Antarctica. (PhD thesis, University of Washington)

MS received 9 July 2011 and accepted in revised form 16 February 2012. 